\title{
Poly(alkylene oxide) Ionomers. II.* Solution Co- and Terpolymerization of Trioxane for the Preparation of Poly(oxymethylene) Ionomers
}

\author{
L. DeMejo, W. J. MacKnight, and O. Vogl \\ Polymer Science and Engineering Department, University of Massachusetts, \\ Amherst, Massachusetts 01003, U.S.A.
}

(Received March 23, 1978)

\begin{abstract}
Solution polymerization of trioxane (TO) with 1, 3-dioxolane (DO) gave copolymers of various comonomer compositions. TO was also copolymerized with ethyl glycidate (EG) and terpolymerized with DO and EG to polymers of low EG content. The copolymers were acetate-endcapped or base-treated to give stable co- and terpolymers. The treatment of EG containing poly(oxymethylene) (POM) copolymers with sodium hydroxide in methanol at elevated temperatures gave POM ionomers. The polymers were characterized by their infrared and PMR spectra for their general structure and co- and terpolymer composition. POM copolymers with only EG as comonomer showed low base stability but those which contained ethylene oxide (EO), either alone or in combination with EG, gave polymers of high base stability.

KEY WORDS Poly(oxymethylene) / Trioxane / 1, 3-Dioxolane / Ethyl Glycidate / Terpolymers / Ionomers / Acetate Endcapping / Base Stability /
\end{abstract}

Ionomers are copolymer of ethylene and 20 $30-\mathrm{mol} \%$ methacrylic or acrylic acid completely or partially neutralized with sodium hydroxide, ${ }^{1}$ or with phosphonate and sulfonate ${ }^{2,3}$ groups.

Ionomers based on the poly(oxymethylene) (POM) backbone chain have been described and some mechanical and spectroscopic properties have been measured. ${ }^{4-10}$ One method for the preparation of the copolymers of $\mathrm{TO}$ and $\mathrm{EG}^{5}$ was a copolymerization technique which consisted of mixing the monomers and the initiator in the gas phase $^{4,5}$ above the ceiling temperature of polymerization of the comonomers and then cooling the initiated monomers ${ }^{11}$ to cause polymerization. A high molecular weight copolymer of TO and EG was prepared which could be acetate-capped or base-treated to give directly the ionomer. The ionomer could be converted into the free acid with acetic acid or it could be transformed into other polymeric alkali salts with the corresponding metal chlorides in aqueous suspension. ${ }^{6}$

Other POM ionomers were prepared by the reac-

* Part I: L. DeMejo, W. J. MacKnight, and O. Vogl, Polymer (London), 19, (No. 8), 956 (1978). tion of epichlorohydrin-TO copolymers with thioglycolate. $^{8,9}$ This method has advantages in that copolymers of TO and epichlorohydrin can be readily prepared at various comonomer compositions. On the other hand, the thioglycolate treatment is cumbersome and, as other polymer reactions, not always complete. Copolymers of styrene oxide-TO could undergo numerous substitution reactions on the benzene rings of styrene in spite of the acid sensitivity of the POM backbone chain. $^{12}$

The advantage of the gas-phase copolymerization of TO and EG is that larger quantities of copolymers of relatively uniform molecular weight distribution and comonomer composition can be prepared. The base stability of this polymer is relatively low and the molecular weight of the basestable polymer is low, indicating that the polymers were "blocky" and little transacetalization occurred and that EG was preferentially incorporated in the copolymer in the early part of the polymerization. The latter stage of the copolymerization was essentially a homopolymerization of the TO. Another advantage of polymerization by mixing in the vapor phase is that larger quantities of poly- 
mers are easily prepared and that both the change to various copolymer compositions and the change in initiator concentration are readily achieved.

Solution and bulk copolymerization of TO with suitable comonomers, studied extensively for epoxides and 1,3-dioxolane which have no functional groups, have advantages over polymerization technique from the gas phase. Comonomers and initiators of low volatility may be used and copolymers which are more "randomized" by transacetalization can be prepared. ${ }^{7}$ The uniformity and dependability of run to run variations of individual copolymer preparations are, low.

It was the objective of this work to prepare coand terpolymers of TO, DO, and EG in solution or in the bulk in order to prepare copolymers and terpolymers which could then be characterized or hydrolyzed with sodium hydroxide to ionomers. In subsequent work the properties of the polymers will be measured by calorimetric, dynamic mechanical, and dielectric techniques.

\section{EXPERIMENTAL PART}

\section{Materials}

Monomers. Trioxane (Celanese Research Co.) (TO) was recrystallized from dichloromethane and distilled from sodium, in the presence of a small amount of benzophenone, immediately before use (Karl Fischer analysis: $\sim 60$ ppm $\mathrm{H}_{2} \mathrm{O}$ ). 1, 3Dioxolane (Eastman Organic Chemicals) (DO) was distilled from lithium aluminum hydride before

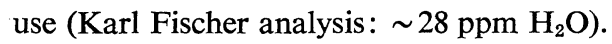

Ethyl glycidate (EG) was prepared in 50-60\%yield from ethyl acrylate by epoxidation with $90-\%$ $\mathrm{H}_{2} \mathrm{O}_{2}$ and trifluoroacetic acid anhydride.

Initiators. Gaseous boron trifluoride (Matheson Products) was used as supplied. Boron trifluoridediethyl etherate (Aldrich Chemical Co.), antimony pentachloride (Ventron Alfa Products) (bp $86^{\circ} \mathrm{C}$, $30 \mathrm{~mm}$ ) and trifluoromethane sulfonic acid (Aldrich Chemical Co.) (bp $\left.76^{\circ} \mathrm{C}, 30 \mathrm{~mm}\right)$ (TFS) were distilled through a Vigreux column and stored in the refrigerator, in tightly capped bottles, before use.

Reagents. Ethyl acrylate (Aldrich Chemical Co.), propionic anhydride (Aldrich Chemical Co.) (bp $\left.68^{\circ} \mathrm{C}, 25 \mathrm{~mm}\right)$ and triethylamine (Eastman Kodak Co.) were distilled before use. Trifluoroacetic anhydride (Aldrich Chemical Co.), 90-\% hydrogen peroxide (FMC Corp.), glacial acetic acid (Fisher Scientific Co.), $d l-\alpha$-pinene (Aldrich Chemical Co.), and tributylamine (Aldrich Chemical Co.) were used without further purification.

All solid reagents, including the metal halides, bases, buffers, and drying agents, were obtained from the Fisher Scientific Company or from Ventron Alfa Products and used as supplied.

1,2-Dichloroethane (Aldrich Chemical Co.), dichloromethane (Fisher Scientific Co.), and 1, 4dioxane (Mallinckrodt Chemical Works) were distilled from lithium aluminum hydride before use [Karl Fisher analysis (1, 2-dichloroethane): $<40$ ppm $\mathrm{H}_{2} \mathrm{O}$ ]. When dry methanol and ethanol were required, these solvents were refluxed over calcium oxide for $48 \mathrm{~h}$, distilled from sodium and stored over molecular sieves. Dimethylformamide (99\% pure) and benzyl alcohol (Aldrich Chemical Co.) were used as supplied.

Polymer Solvents. p-Chlorophenol (mp 38$40^{\circ} \mathrm{C}$ ) (Eastman Kodak Co.), was distilled at reduced pressure (bp $94^{\circ} \mathrm{C}, 8 \mathrm{~mm}$ ). For viscosity measurements, two percent by weight of $d l-\alpha-$ pinene was added to the $p$-chlorophenol. Deuterated and undeuterated hexafluoro-2-propanol (Aldrich Chemical Co.), hexafluoroacetone sesquihydrate (Aldrich Chemical Co.), and octafluoro-1-pentanol (Pfaltz \& Bauer Inc.) were used without further purification. Hexafluoroacetone sesquihydrate was buffered with triethylamine (one percent by weight) before use.

\section{Measurements}

Most infrared spectra were measured on a PerkinElmer 727 Spectrophotometer, and some polymer spectra on a Perkin-Elmer 283 Spetrophotometer. Solid samples were measured as thin films $(\sim 1-\mathrm{mm}$ thick) or as pressed pellets and liquid samples between sodium chloride plates. The peak assignments were made to the nearest 0.1 micron.

Gas chromatograms of liquid samples were recorded on a Varian 920 Aerograph with helium as the carrier gas.

The NMR spectra of low molecular weight compounds were measured on a $60-\mathrm{MHz}$ R-24 Hitachi Perkin-Elmer Spectrometer, polymer spectra in deuterated hexafluoroacetone sesquihydrate on a 90-MHz R-32 Perkin-Elmer Spectrometer.

\section{Solution Polymerizations}

a. Trioxane-1, 3-Dioxolane Copolymers. TO 
$(102.5 \mathrm{~g}, 1.4 \mathrm{~mol})$ was distilled from sodium directly into a three-necked round-bottom flask equipped with a glass stopper and a stirring rod and shaft unit. At the end of the distillation, a rubber septum was quickly placed around the flask neck through which the TO had been introduced, the entire assembly was transferred to a dry box, and freshly distilled, dry 1,2-dichloroethane $(240 \mathrm{~m} l)$ was added to the TO. The flask was shaken until all the TO had dissolved, $11.2 \mathrm{~g}$ $(0.15 \mathrm{~mol})$ of DO was added and the septum was quickly fitted into place.

For each run, the initiator solution was prepared freshly by syringing $0.1 \mathrm{~m} l\left(1.3 \times 10^{-3} \mathrm{~mol}\right)$ of TFS through a rubber septum, into a vial containing $14 \mathrm{ml}$ of 1,2-dichloroethane with dry nitrogen blanketing.

The polymerization flask, containing monomers and the solvent, was rapidly transferred from the dry box and immersed into an oil bath at $40^{\circ} \mathrm{C}$. Rapid stirring was begun as a slow stream of dry nitrogen was passed through the flask. The initiator solution $(9 \mathrm{~m} l)$ was added through the septum into the flask over a period of $1 \mathrm{~min}$. After two additional minutes the reaction mixture became cloudy, the reaction was allowed to proceed for three hours during which time precipitation of polymer continued, the mixture was filtered, washed with a $5-\%$ sodium bicarbonate solution, water and finally with methanol. It was dried at $65^{\circ} \mathrm{C}(30 \mathrm{~mm})$ for $16 \mathrm{~h}$ to give $111 \mathrm{~g}$ ( $97-\%$ yield) of polymer. (TD-A).

Crude copolymer $(30 \mathrm{~g})$ was allowed to react with $7.5 \mathrm{~g}$ of potassium hydroxide in $450 \mathrm{ml}$ of benzyl alcohol at $160^{\circ} \mathrm{C}$ to remove the base-unstable portions. Nitrogen was slowly bubbled into the reaction mixture to minimize polymer oxidation during the one-hour reaction. A fine white solid ( $25 \mathrm{~g}, 83-\%$ yield) was finally obtained.

Copolymers TD-B and TD-C, each incorporating increasingly higher levels of $\mathrm{DO}$, were prepared and stabilized in the same manner. Thus, $90.0 \mathrm{~g}$ $(1 \mathrm{~mol})$ of TO and $18.5 \mathrm{~g}(0.25 \mathrm{~mol})$ of $\mathrm{DO}$, in
$250 \mathrm{ml}$ of dichloroethane, and $0.06 \mathrm{~mol}(8.5 \times$ $\left.10^{-5} \mathrm{~mol}\right)$ of TFS gave $104 \mathrm{~g}(96 \%$ yield $)$ of TD-B (5-min induction period, $95-\%$ base-stable copolymer).

TD-C was obtained in $67-\%$ yield from $42.2 \mathrm{~g}$ $(0.47 \mathrm{~mol})$ of TO with $14.8 \mathrm{~g}(0.20 \mathrm{~mol})$ of DO after $0.03 \mathrm{~m} l\left(4.6 \times 10^{-4} \mathrm{~mol}\right)$ of TFS were added to the two monomers dissolved in $125 \mathrm{ml}$ of 1, 2dichloroethane $(15-\mathrm{min}$ induction period, base stability $87 \%$ ).

The intrinsic viscosities of the base-stable copolymers were measured at room temperature in a hexafluoroacetone-water mixed solvent (molar ratio, $1 / 1.5)$ (Table I). ${ }^{13}$

The NMR spectra of the 3 copolymers (deuterated hexafluoroacetone sesquihydrate, $35^{\circ} \mathrm{C}$ ) showed $\delta: 4.8$ to $5.2\left(\mathrm{CH}_{2} \mathrm{O}, 2\right) ; 3.7$ to 4.0 $\left(\mathrm{CH}_{2} \mathrm{CH}_{2} \mathrm{O}, 4\right)$. The mole percent of oxyethylene units determined from the integrated NMR signals, is also listed in Table I. The NMR peak assignments in the copolymers are confirmed by a comparison of the spectrum for TD-C (Figure 1a) with those for a "gas phase" TO homopolymer ${ }^{17}$ (Figure 1b) and a poly-DO prepared in bulk using antimony pentachloride as the cationic initiator (Figure 1c).

The ratio of the 7.8- $\mu$ absorbance (backbone ethylene torsion vibration) to the standard $4.3-\mu$ absorbance, in the infrared, remained unchanged at 1.7 for samples TD-A and TD-B but increased to 2.0 for TD-C (Figure 2). A relatively weak hydroxyl absorption $(2.7 \mu-3.0 \mu)$ was observed in all three cases.

b. Trioxane-Ethyl Glycidate Copolymers. An attempt was made to prepare a TO-EG copolymer in solution. Accordingly $1.5 \mathrm{~g}\left(1.7 \times 10^{-2} \mathrm{~mol}\right)$ of TO and $0.25 \mathrm{~g}\left(2.1 \times 10^{-3} \mathrm{~mol}\right)$ of EG were dissolved in $3.3 \mathrm{ml}$ of 1, 2-dichloroethane and reacted with $0.001 \mathrm{ml}\left(1.5 \times 10^{-5} \mathrm{~mol}, 0.09 \mathrm{~mol} \%\right)$ of TFS for $3 \mathrm{~h}$ at $40^{\circ} \mathrm{C}$. No polymer was recovered from the reaction mixture. The same amount of TO, dissolved in $3.3 \mathrm{ml}$ of 1,2 -dichloroethane at $40^{\circ} \mathrm{C}$, gave an $80-\%$ yield of homopolymer, $5 \mathrm{~min}$ after

Table I. Characterization of trioxane-1, 3-dioxolane copolymers

\begin{tabular}{lccc}
\multicolumn{1}{c}{ Sample designation } & TD-A & TD-B & TD-C \\
\hline Intrinsic viscosity, $\mathrm{d} l / \mathrm{g}$ & 2.3 & 1.9 & 3.2 \\
Weight-average molecular weight & $9.8 \times 10^{4}$ & $7.2 \times 10^{4}$ & $1.6 \times 10^{5}$ \\
$\mathrm{CH}_{2} \mathrm{CH}_{2} \mathrm{O}$ units/100 $\mathrm{CH}_{2} \mathrm{O}$ units based on PMR & 2.2 & 3.2 & 4.2 \\
\hline
\end{tabular}


L. Demejo, W. J. MacKnight, and O. Vogl

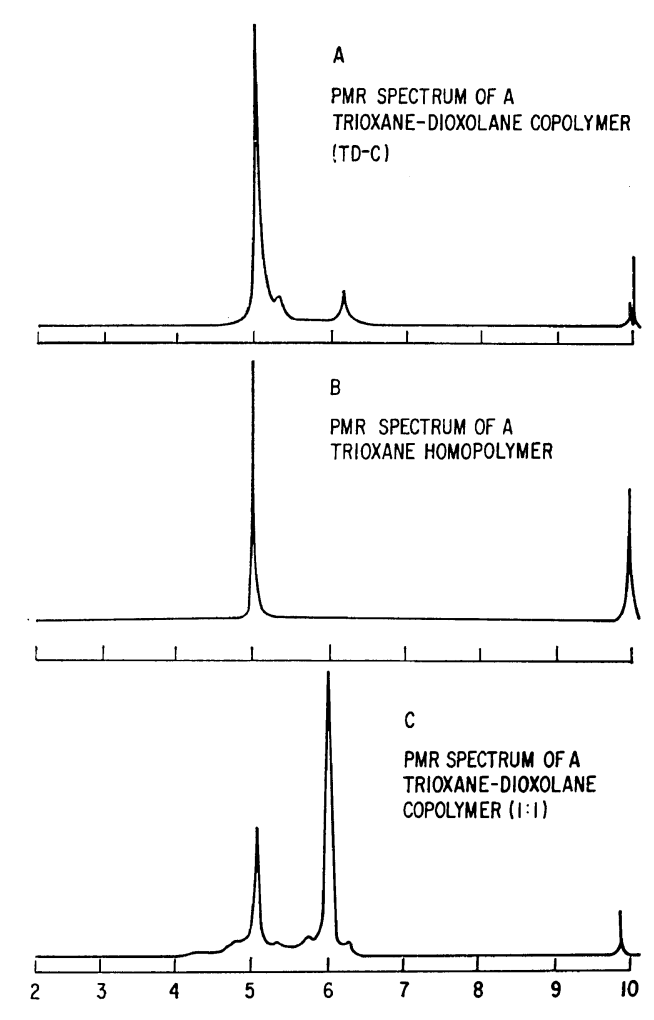

Figure 1. NMR spectra of trioxane-1, 3-dioxolane copolymers: A, copolymer of low DO content (TD-C); $\mathrm{B}$, trioxane homopolymer; $\mathrm{C}, 1: 1$ copolymer.

the addition of $0.001 \mathrm{~m} l$ of the initiator.

High yields of copolymer could be obtained by adding less comonomer, more initiator and by adjusting the reaction temperature close to the melting point of TO. In a representative example, $11.4 \mathrm{~g}\left(1.3 \times 10^{-1} \mathrm{~mol}\right)$ of $\mathrm{TO}, 0.75 \mathrm{~g}\left(6.5 \times 10^{-3}\right.$ $\mathrm{mol}, 5 \mathrm{~mol} \%)$ of EG and $0.006 \mathrm{ml}\left(9.3 \times 10^{-5} \mathrm{~mol}\right.$, $0.07 \mathrm{~mol} \%$ ) of TFS were allowed to react in $25 \mathrm{ml}$ of 1,2-dichloroethane for three hours at $60^{\circ} \mathrm{C}$ to give a $93-\%$ yield of copolymer with a $19-\%$ basestable fraction.

c. Trioxane-Ethyl Glycidate-1,3-Dioxolane Terpolymers. In a series of experiments, ethylene oxide units were introduced randomly along the backbone of polymer chains containing methylene oxide units and 1-thoxycarbonyloxyethylene units. The purpose of these experiments was to obtain ionizable polymers, in moderate yields, that exhibited high base stabilities. All reactions, except one, were carried out in $25 \mathrm{ml}$ of 1,2-dichloroethane for three hours at $60^{\circ} \mathrm{C}$. The results of
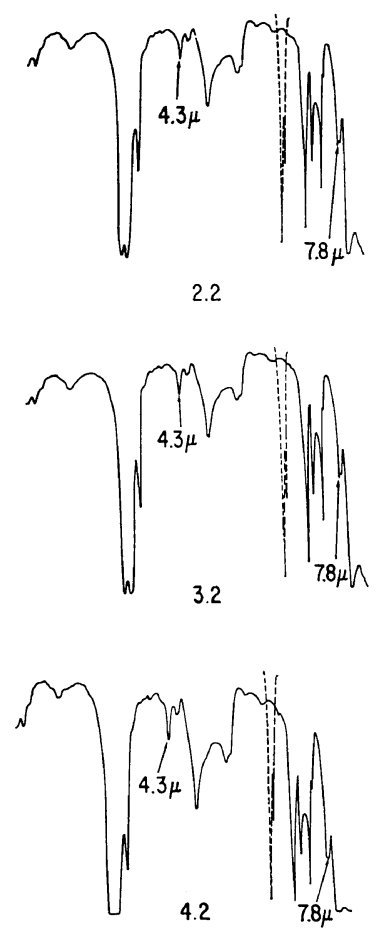

Figure 2. Infrared spectra of trioxane-1, 3-dioxolane copolymers.

these experiments are summarized in Table II.

In the course of three scale-up procedures, the amount of EG in the feed was varied from 5 to 15 mol percent while the amount of DO was maintained constant $(10 \mathrm{~mol} \%)$. The resulting terpolymers were labeled TED-A, TED-B, and TED$\mathrm{C}$, respectively. The TO and DO monomers, dissolved in 1,2-dichloroethane, were stirred vigorously in a three-necked round-bottom flask, immersed in an oil bath at $65^{\circ} \mathrm{C}$. The boron trifluoride diethyl etherate initiator was added as a solution in 1,2-dichloroethane through a rubber septum directly into the reaction medium. After approximately 15 minutes, the solution in the polymerization flask became cloudy. At this point, the EG was rapidly added to the reaction mixture through an addition funnel. The reaction was allowed to proceed for a specified period of time after which stirring was discontinued and the flask was removed from the oil bath.

The workup and drying procedures were the same as those used for the recovery of copolymers TD-A, TD-B, and TD-C. The reaction conditions 
Poly(alkylene oxide) Ionomers. II.

Table II. Solution polymerization of trioxane, ethyl glycidate, and 1, 3-dioxolane

\begin{tabular}{cccccc}
\hline $\begin{array}{c}\text { Trioxane, } \\
\text { mol \% }\end{array}$ & $\begin{array}{c}\text { Ethyl glycidate, } \\
\text { mol \% }\end{array}$ & $\begin{array}{c}1,3-\text { Dioxolane, } \\
\text { mol \% }\end{array}$ & $\begin{array}{c}\text { Initiator, } \\
\text { mol \% }\end{array}$ & $\begin{array}{c}\text { Yield, } \\
\%\end{array}$ & $\begin{array}{c}\text { Base stability, } \\
\%\end{array}$ \\
\hline 95 & 5 & 0 & $0.07^{\mathrm{b}}$ & 93 & 19.0 \\
85 & 5 & 10 & $0.10^{\mathrm{b}}$ & 28 & - \\
85 & 5 & 10 & $0.07^{\mathrm{c}}$ & 62 & 85.5 \\
85 & 5 & 10 & $0.07^{\mathrm{c}}$ & 62 & 95.0 \\
90 & 5 & 5 & $0.05^{\mathrm{c}}$ & 90 & 41.5 \\
75 & 15 & 10 & $0.06^{\mathrm{c}}$ & $40^{\mathrm{d}}$ & 69.5 \\
75 & 10 & 15 & $0.12^{\mathrm{c}}$ & 52 & 78.5
\end{tabular}

a Polymer recovered after high temperature exposure to potassium hydroxide.

b Trifluoromethane-sulfonic acid.

c Boron trifluoride diethyl etherate.

d Thirty minutes at $60^{\circ} \mathrm{C}$ in $15 \mathrm{ml}$ of 1,2 -dichloroethane.

Table III. Synthesis of trioxane-ethyl glycidate-1, 3-dioxolane terpolymers

\begin{tabular}{lccc}
\hline \multicolumn{1}{c}{ Sample designation } & TED-A & TED-B & TED-C \\
Trioxane, $\mathrm{g}(\mathrm{mol})$ & $184.0(2.04)$ & $161.9(1.80)$ & $178.5(1.98)$ \\
Ethyl glycidate, $\mathrm{g}(\mathrm{mol})$ & $12.4(0.11)$ & $26.1(0.23)$ & $45.9(0.40)$ \\
1, 3-Dioxolane, $\mathrm{g}(\mathrm{mol})$ & $16.8(0.23)$ & $16.6(0.23)$ & $19.5(0.26)$ \\
Initiator, $\mathrm{m} l$ (mol), Solvent, $400 \mathrm{ml}$ & $0.20\left(1.6 \times 10^{-3}\right)$ & $0.18\left(1.5 \times 10^{-3}\right)$ & $0.22\left(1.8 \times 10^{-3}\right)$ \\
Conditions & $2.0 \mathrm{~h}$ at $65^{\circ} \mathrm{C}$ & $2.5 \mathrm{~h}$ at $65^{\circ} \mathrm{C}$ & $3.0 \mathrm{~h}$ at $65^{\circ} \mathrm{C}$ \\
Yield, in percent & 63 & 63 & 50
\end{tabular}

and yields for these experiments are listed in Table III.

A Parr reactor was charged with $15 \mathrm{~g}$ of crude terpolymer (TED-A) and $300 \mathrm{~m} l$ of ethanol. The reactor was flushed with nitrogen and then pressurized with nitrogen to approximately $40 \mathrm{psi}$. The contents of the reactor were heated to $160^{\circ} \mathrm{C}$ and stirred at that temperature for $1 \mathrm{~h}$. At the end of the reaction, the autoclave was lifted out of the variac heating unit and immersed in a bucket of ice-water, causing the thermally stabilized terpolymer to rapidly precipitate out of the solution. The solid was washed several times with methanol and dried at $60^{\circ} \mathrm{C}(30 \mathrm{~mm})$ for $16 \mathrm{~h}$. The procedure was repeated for TED-B and TED-C. The yields of heat treated TED-A, TED-B, and TED-C were 91,96 , and $95 \%$, respectively. d. Ionic Derivatives of the Terpolymers. Thirty $\mathrm{g}$ of crude TED-A terpolymer were allowed to react with $4.5 \mathrm{~g}(0.11 \mathrm{~mol})$ of sodium hydroxide in a methanol-water mixture $(400 \mathrm{ml} / 250 \mathrm{ml})$ for $1 \mathrm{~h}$ at $160^{\circ} \mathrm{C}$. The reaction was carried out in a Parr reactor at approximately 240 psi. Before heating the reactants to $160^{\circ} \mathrm{C}$, the reactor was pressurized with a slight positive nitrogen pressure. At the end of the reaction, the contents of the Parr reactor were rapidly cooled to room temperature by immersing the stainless steel reaction vessel into a bucket of ice-water. The solid precipitate was filtered, washed with water and with methanol and finally dried at $60^{\circ} \mathrm{C}(30 \mathrm{~mm})$ for $15 \mathrm{~h}$. The sodium salts of TED-B and TED-C were prepared in exactly the same way. The yields of the TED-A, TED-B, and TED-C sodium salts were 93,83 , and

Table IV. Characterization of the ionic derivatives of trioxane-ethyl glycidate-1, 3-dioxolane terpolymers

\begin{tabular}{lccc}
\multicolumn{1}{c}{ Sample designation } & TED-A (Salt) & TED-B (Salt) & TED-C (Salt) \\
\hline Intrinsic viscosity, $\mathrm{d} l / \mathrm{g}$ & 0.30 & 0.28 & 0.27 \\
Weight-average molecular weight ${ }^{\mathrm{a}}$ & $1.50 \times 10^{4}$ & $1.40 \times 10^{4}$ & $1.40 \times 10^{4}$ \\
$\mathrm{Mol} \%-\mathrm{CH}_{2} \mathrm{CH}\left(\mathrm{COO}^{-} \mathrm{Na}^{+}\right) \mathrm{O}$ - based on $\mathrm{Na}$ analysis & 0.9 & 1.7 & 2.0 \\
\hline
\end{tabular}

\footnotetext{
a Based on ref 14 .
} 
$88 \%$, respectively. Their intrinsic viscosities (at $110^{\circ} \mathrm{C}$ in octafluoropentanol) and respective weight-average molecular weights are given in Table IV. The amount of 1-sodium carboxylate oxyethylene units in the sodium salts (mole percent) are also shown in Table IV.

e. Acid Derivatives of the Terpolymers. Sodium salts of the three terpolymers $(5 \mathrm{~g})$ were stirred vigorously, in separate round-bottom flasks, each with $5 \mathrm{~m} l$ of glacial acetic acid, $45 \mathrm{~m} l$ of deionized water and $200 \mathrm{~m} l$ of dioxane, for $3 \mathrm{~h}$, at room temperature, under nitrogen. The filtered solids were washed repeatedly with water, then with methanol and dried under vacuum for $16 \mathrm{~h}$ at $60^{\circ} \mathrm{C}$. The yields of the corresponding polymeric acids were $90 \%$ or higher (taking into account the replacement of a sodium atom with a hydrogen atom during the reaction). The intrinsic viscosity (at $110^{\circ} \mathrm{C}$ in octafluoropentanol) was $0.3 \mathrm{~d} l / \mathrm{g}$ for all three acids (unchanged from that of the three salt precursors).

Figure 3 shows the infrared spectra of the heat treated ester, the sodium salt and the acid derivatives of TED-A. Two new absorptions between
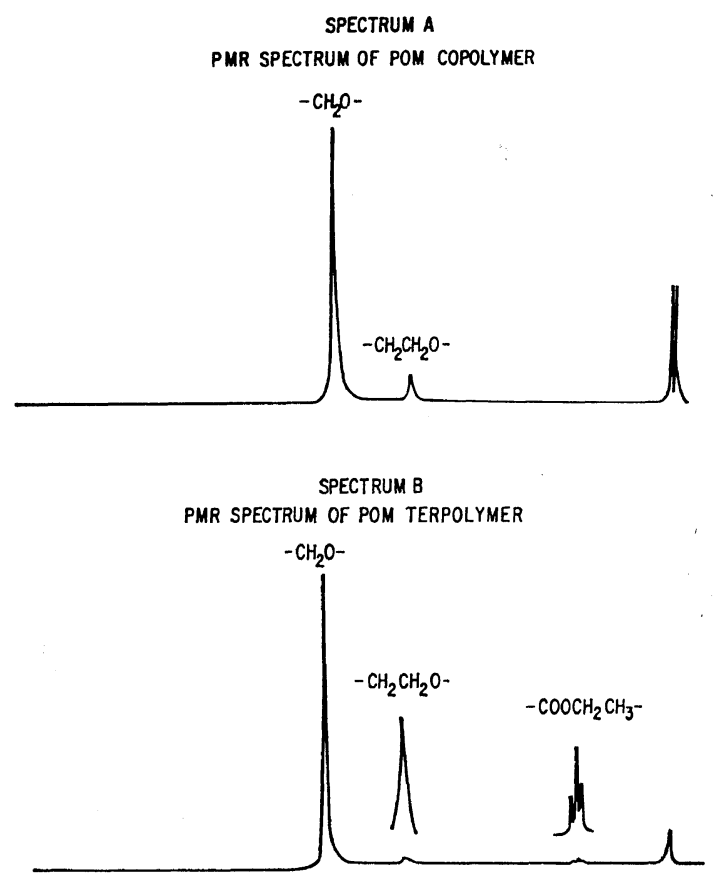

Figure 3. PMR spectra of POM co- and terpolymers: A, trioxane-1, 3-dioxolane copolymers; B, trioxane1, 3-dioxolane-ethyl glycidate terpolymer.
6.2 and $6.3 \mu$ and between 7.0 and $7.1 \mu$, due to the carboxylate anion in the salt, are seen to replace the 5.8- $\mu$ absorption due to the ester carbonyl. The spectrum of the polymeric acid shows a new absorption at $5.8 \mu$ and a weak absorption at $6.2 \mu$, due possibly to the carboxylate anion of the salt precursor.

Table $\mathrm{V}$ shows the results of the sodium analyses of the salt and acid derivatives of TED-A, TED-B, and TED-C.

Table V. Sodium content in the derivatives of trioxane-ethyl glycidate-dioxolane terpolymers

\begin{tabular}{lccc}
\hline Sample designation & TED-A & TED-B & TED-C \\
\hline wt $\% \mathrm{Na}$ in the salts & 0.55 & 1.01 & 1.22 \\
wt $\% \mathrm{Na}$ in the acids & 0.10 & 0.10 & 0.10 \\
\hline
\end{tabular}

\section{Bulk Polymerization}

Bulk polymerizations to prepare TO-EG copolymers were also investigated. In one attempt, $1.5 \mathrm{~g}\left(1.7 \times 10^{-3} \mathrm{~mol}\right)$ of TO, $0.25 \mathrm{~g}\left(2.1 \times 10^{-3} \mathrm{~mol}\right)$ of EG and $0.001 \mathrm{~m} l\left(1.5 \times 10^{-5} \mathrm{~mol}\right)$ of TFS (added as a solution in $0.1 \mathrm{~m} l$ of 1,2-dichloroethane) were utilized, and the reaction was allowed to proceed for $2 \mathrm{~h}$ at $70^{\circ} \mathrm{C}$. A $24-\%$ yield of polymer was obtained. After high temperature exposure to potassium hydroxide, $11 \%$ of stable polymer was recovered.

Additional attempts to copolymerize EG with TO, in the presence of higher levels of TFS, gave low yields of products with low base stable fractions. When $1.5 \mathrm{~g}$ of TO was allowed to react with $0.001 \mathrm{~m} l$ of TFS (added as a solution in $0.1 \mathrm{~m} l$ of 1,2-dichloroethane) at $70^{\circ} \mathrm{C}$, gelation of the reaction mixture occurred within $3 \mathrm{~min}$ and an $85-\%$ yield of homopolymer could be isolated. These results are summarized in Table VI.

Table VI. Bulk polymerization of trioxane and ethyl glycidate reaction conditions; $15 \mathrm{~min}$ at $70^{\circ} \mathrm{C}$

\begin{tabular}{ccccc}
$\begin{array}{c}\text { Trioxane, } \\
\text { mol \% }\end{array}$ & $\begin{array}{c}\text { Ethyl } \\
\text { glycidate, } \\
\text { mol \% }\end{array}$ & $\begin{array}{c}\text { Initiator, } \\
\text { mol \% }\end{array}$ & Yield, & $\begin{array}{c}\text { Base } \\
\text { stability, } \\
\%\end{array}$ \\
\hline 95 & 5 & 15.9 & 58 & 33 \\
90 & 10 & 26.0 & 32 & 36 \\
85 & 15 & 9.3 & 44 & 5 \\
\hline
\end{tabular}


Poly(alkylene oxide) Ionomers. II.

\section{RESULTS AND DISCUSSION}

Copolymers of TO and DO, TO and EG and terpolymers of TO, DO, and EG were prepared in solution with $\mathrm{BF}_{3}$ and TFS as initiators. While TFS was effective for TO-DO copolymerization, it was not very effective when EG was the co- or termonomer. The polymers were heat-treated or base-degraded to stable POM polymers.

TO-DO copolymers of three different compositions, 7,11 , and $14 \mathrm{~mol} \%$ of DO, were prepared with TFS as the initiator in yields in excess of $95 \%$. The base stability of these materials was greater than $85 \%$ and the molecular weight as judged by the intrinsic viscosity was near or greater than $2 \mathrm{~d} l / \mathrm{g}$, which corresponds to a molecular weight of 100,000 . The characteristics of these polymers are shown in Table I.

Penczek and coworkers ${ }^{15}$ have shown that the best results, i.e., short induction periods, high polymerization rates, high degrees of polymerization and a low content of unstable fraction, comparable with other POM copolymers, have been obtained when TO was copolymerized with $\mathrm{DO}$ in the presence of the ester or anhydride derivatives of TFS. The excellent performance of these systems as cationic initiators was ascribed to the low nucleophilicity and stability of the $\mathrm{CF}_{3} \mathrm{SO}_{2} \mathrm{O}^{\ominus}$ anion. The occurrence of transacetalization reactions in the solution polymerization of cyclic acetals initiated by cationic species from TFS is well established. In view of these facts, the TFS initiating system was selected in an attempt to prepare random copolymers in high yield exhibiting high molecular weights and base stabilities (eq 1). The results of the present work showed that these attempts proved successful. It has also been shown ${ }^{16}$

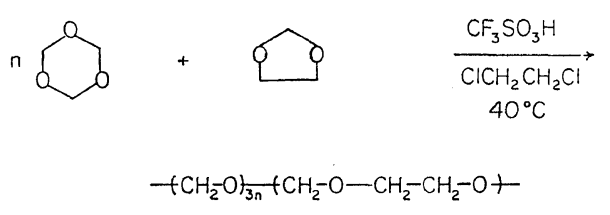

that in the copolymerization of TO with DO, initiated by cationic species, TO was more reluctant to participate in the initiation step. On the basis of this finding, the possible initiation step was the reaction of TFS with DO (eq 2).

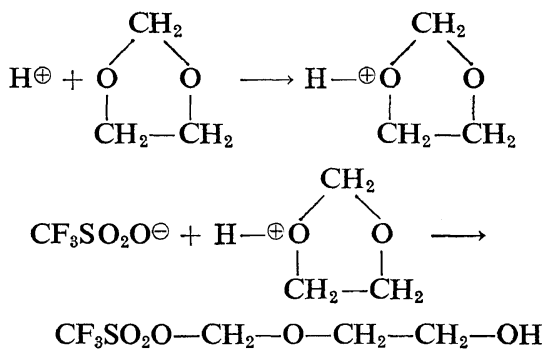

Two phenomena were characteristic of cyclic acetal polymerizations initiated with the anhydride of TFS: shorter induction periods were observed at comparable conditions than with triphenyl methylium salts $\left(\mathrm{AsF}_{6} \ominus\right.$ or $\mathrm{SbF}_{6} \ominus$ anions), and much lower concentrations of superacid anhydride were needed to achieve the same polymerization rates than with the triphenylmethyl cation.

Table VII shows a comparison of the results for the copolymerization of TO with DO in the presence of TFS, its anhydride or other types of cationic initiators. The copolymerizations ${ }^{15}$ were conducted at $60^{\circ} \mathrm{C}$ in cyclohexane as the solvent and in the presence of 2.0 weight percent (sum of

Table VII. Cationic ring-opening copolymerization of trioxane with 1, 3-dioxolane

\begin{tabular}{|c|c|c|c|c|c|c|}
\hline \multirow{2}{*}{ Initiator } & \multirow{2}{*}{$\begin{array}{l}\text { Initiator } \\
\text { concn, } \\
\text { mol } / l\end{array}$} & \multirow{2}{*}{$\begin{array}{c}\text { Comonomer conch } \\
\text { (trioxane }+\mathrm{DO}), \\
\mathrm{mol} / l\end{array}$} & \multirow{2}{*}{$\begin{array}{l}\text { Induction } \\
\text { period, } \\
\text { sec }\end{array}$} & \multirow[t]{2}{*}{ Mol wt } & \multicolumn{2}{|c|}{$\%$ Yield } \\
\hline & & & & & $\begin{array}{l}\text { Stable } \\
\text { fraction }\end{array}$ & $\begin{array}{l}\text { Unstable } \\
\text { fraction }\end{array}$ \\
\hline$\left(\mathrm{CF}_{3} \mathrm{SO}_{2}\right)_{2} \mathrm{O}^{\mathrm{a}}$ & $8 \times 10^{-4}$ & $7.0+0.4$ & 240 & $1.4 \times 10^{5 \mathrm{c}}$ & 74 & 6 \\
\hline$\left(\mathrm{CF}_{2} \mathrm{SO}_{2}\right)_{2} \mathrm{O}^{\mathrm{a}}$ & $1 \times 10^{-3}$ & $7.0+0.4$ & 120 & $1.4 \times 10^{5} \mathrm{c}$ & 82 & 7 \\
\hline $\mathrm{CF}_{3} \mathrm{SO}_{2} \mathrm{OH}^{\mathrm{b}}$ & $5 \times 10^{-3}$ & $4.6+0.6$ & 120 & $9.8 \times 10^{4} d$ & 81 & 16 \\
\hline $\mathrm{CF}_{3} \mathrm{SO}_{2} \mathrm{OH}^{\mathrm{b}}$ & $3 \times 10^{-3}$ & $4.0+1.0$ & 300 & $7.2 \times 10^{4 d}$ & 91 & 5 \\
\hline $\mathrm{CF}_{3} \mathrm{SO}_{2} \mathrm{OH}^{\mathrm{b}}$ & $4 \times 10^{-3}$ & $4.0+1.6$ & 900 & $1.6 \times 10^{5 \mathrm{~d}}$ & 58 & 9 \\
\hline $\mathrm{BF}_{3} \mathrm{O}\left(\mathrm{C}_{4} \mathrm{H}_{9}\right)_{2}^{\mathrm{a}}$ & $4 \times 10^{-2}$ & $7.3+0.4$ & 120 & $8.8 \times 10^{4} \mathrm{c}$ & 75 & 6 \\
\hline$\left(\mathrm{C}_{6} \mathrm{H}_{5}\right)_{3} \mathrm{C} \oplus \mathrm{AsF}_{8} \ominus \mathrm{a}$ & $6 \times 10^{-3}$ & $6.5+0.3$ & 200 & $8.6 \times 10^{4} \mathrm{c}$ & 78 & 6 \\
\hline
\end{tabular}

a Reference 15 . b This work. c $\bar{M}_{n}$. d $\bar{M}_{w}$. 
monomers) of poly(ethylene oxide) with $\bar{M}_{n}=$ 40,000. All copolymerizations listed in Table VII were carried out for three hours except for the one initiated with the triphenyl methylium salt $\left(\mathrm{AsF}_{6} \ominus\right.$ anion) which lasted for two and a half hours. The base stabilization of some copolymers was carried out in benzyl alcohol at $150^{\circ} \mathrm{C}$ in the presence of tri- $n$-butylamine for $30 \mathrm{~min}$. The other copolymers were stabilized according to the procedure described earlier (eq 3).

$$
\begin{aligned}
& -\mathrm{CH}_{2}-\mathrm{CH}_{2}-\mathrm{O}+\mathrm{CH}_{2}-\mathrm{O}+\mathrm{H} \quad \frac{\mathrm{KOH}}{\begin{array}{c}
\text { benzyl alcohol } \\
160^{\circ} \mathrm{C}
\end{array}} \\
& -\mathrm{CH}_{2}-\mathrm{CH}_{2}-\mathrm{O}-\mathrm{H}+\mathrm{n} \mathrm{CH}_{2}=\mathrm{O}
\end{aligned}
$$

The overall performance of the systems initiated with TFS or its anhydride is better than those initiated with other types of cationic initiators, both in terms of molecular weight of the final product and the amount of initiator needed to achieve the same polymerization rates, the same amount of base-unstable fraction and final yields. The induction period increased dramatically in the systems studied in the present work when the amount of DO in the feed was increased from 12 to $30 \mathrm{~mol} \%$ (based on mol TO + mol DO) at approximately the same level of initiator. On the other hand, less initiator was needed to produce similar or better results. In the copolymerization of TO with relatively small amounts of DO systems using TFS or its anhydride, the molecular weights of resulting copolymers were higher than those with complex anions such as $\mathrm{AsF}_{6} \ominus$ (see Table VII).

The moderate yield and high molecular weight obtained for the copolymer with $30 \mathrm{~mol} \%$ of DO (based on mol TO + mol DO) in the feed (TD-C) may be due to the fact that the polymerization was stopped at a relatively low \%-conversion (when copolymer rich in DO was still present). This DO-rich copolymer was still soluble in dichloroethane and may have been removed during the isolation of the insoluble copolymer.

Spectrum A in Figure 4 shows a PMR spectrum of a TO-DO copolymer (deuterated hexafluoroacetone sesquihydrate, $35^{\circ} \mathrm{C}$ ). The major peak ( $\delta 4.8$ to 5.2) corresponds to the two oxymethylene protons and the secondary peak ( $\delta, 3.7$ to 4.0$)$ corresponds to the four oxyethylene protons. Spectra
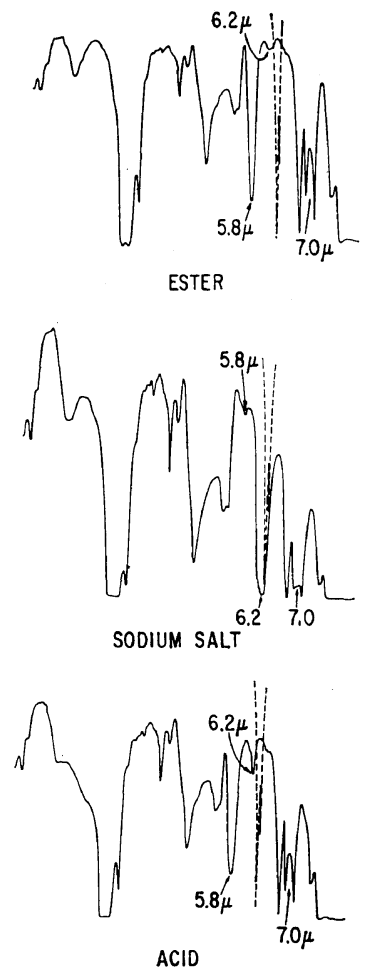

Figure 4. Infrared spectra of POM derivatives: A, ester; $B$, sodium salt; $C$, acid.

Table VIII. Correlation of molecular weight with endgroup analysis by infrared

\begin{tabular}{ccc}
\hline $\begin{array}{c}\text { Sample } \\
\text { designation }\end{array}$ & $\begin{array}{c}\text { Molecular } \\
\text { weight, } \bar{M}_{w}\end{array}$ & $2.9 \mu / 4.3 \mu$ \\
\hline TD-A & $9.8 \times 10^{4}$ & 0.55 \\
TD-B & $7.2 \times 10^{4}$ & 0.60 \\
TD-C & $1.6 \times 10^{5}$ & 0.40 \\
\hline
\end{tabular}

such as these were used to determine the compositions of copolymers TD-A, TD-B, and TD-C as well as the TO-DO copolymer prepared earlier (Part I).

Table VIII shows that the molecular weight of these copolymers was inversely proportional to the concentration of $\mathrm{OH}$ endgroups (Figure 2) [ratio of the $\mathrm{OH}$ absorption (at $2.9 \mu$ ) to the standard POM absorption at $4.3 \mu$ ]. The weak $\mathrm{OH}$ absorption was an indication of the high molecular weight of the copolymers (low hydroxyl endgroup content).

\section{TO-EG Copolymers}

Low yields, a high portion of a base-unstable 
Poly(alkylene oxide) Ionomers. II.

fraction and low molecular weights were seen in products obtained from the solution and bulk polymerization of TO with EG. TO evidently does not copolymerize as readily and effectively with EG to give uniform copolymers under those conditions in which high yields and high molecular weights of TO homopolymers, and high polymer yields with low base-unstable fraction and high molecular weights of TO-DO copolymers were normally observed. With $12 \mathrm{~mol} \%$ of EG and $0.1 \mathrm{~mol} \%$ of TFS, no polymer was obtained but high yields of copolymers could be obtained with less comonomer, for example, with $5 \mathrm{~mol} \%$ of EG. Although the yield of the copolymers was $93 \%$, the base stability was only $20 \%$. It is also possible that, at a higher EG concentration, this comonomer acted as a very effective chain-transfer agent.

In order to prepare copolymers of reasonably high molecular weight and relatively high basestable fractions, terpolymers of TO, EG, and DO were prepared, with $\mathrm{BF}_{3}$ as the initiator (eq 4).

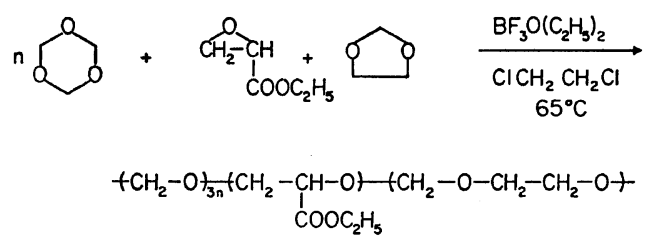

As indicated in Table II, the DO content was normally kept at $10 \mathrm{~mol} \%$ and the initiator approximately $0.1 \mathrm{~mol} \%$. Under these conditions, polymer yields of $40-90 \%$ were obtained with base-stable fractions from $40-95 \%$. In all cases, the induction period was about $15 \mathrm{~min}$.

If the initiator was added to a solution of the three monomers in 1,2-dichloroethane, the yields were the same or lower, and the base stability of the polymers was lower than that obtained from polymers prepared by first adding the initiator to a solution of TO and DO in 1, 2-dichloroethane and waiting for the polymerization to commence before adding the EG monomer (Table I-Examples 3 and 4). Again, in this case, EG may have been acting as a very effective chain-transfer agent.

It was found that when EG was added after the induction period of the copolymerization of TO and DO was completed and the polymerization had commenced, the termonomer EG problems were minimized.

Three specific polymers were prepared with an initial EG feed of 5, 10, and $15 \mathrm{~mol} \%$. The polymer yields of this series was about $60 \%$ and the stability of the individual polymers when heated at $160^{\circ} \mathrm{C}$ in ethanol for one hour was greater than $90 \%$. This treatment removed the thermally unstable hemiacetal endgroup but retained the ester groups of the polymer. Ethanol was used as the solvent for heat treatment because the EG units had ethyl ester groups in the polymer. Normally a heat treatment in methanol at $150^{\circ} \mathrm{C}$ for POM copolymers is preferred, but in our case it was believed that a possibility might exist that an ester exchange could occur with methanol. For the copolymerizations of TO and EG, the sequence of addition of the individual monomers was critical.

The NMR spectra of the heat-treated polymeric esters of TED-A, TED-B, and TED-C (deuterated hexafluoroacetone sesquihydrate, $35^{\circ} \mathrm{C}$ ) showed $\delta$ : 4.8 to $5.2\left(\mathrm{CH}_{2} \mathrm{O}, 2\right): 3.7$ to $4.0\left(\mathrm{CH}_{2} \mathrm{CH}_{2} \mathrm{O}, 4\right.$ and $\left.\mathrm{CH}_{2} \mathrm{CHO}, 2\right): 1.2$ to $1.4\left(\mathrm{COOCH}_{2} \mathrm{CH}_{3}, 3\right)$ (Figure 3, Spectrum B). The NMR spectra of the corresponding POM sodium salts and POM acids showed the same absorptions except for protons of the ethyl group of the ethyl ester. Due to the relatively small amount of 1-ethoxycarbonyloxyethylene units incorporated on the polymer chain, the acid protons in the polymeric acids could not be identified.

The number of 1-ethoxycarbonyloxyethylene units $/ 100$ oxymethylene units was determined by comparing the integrated peak intensities of $\delta 1.2$ $-1.4\left(\mathrm{COOCH}_{2} \mathrm{CH}_{3}, 3\right)$ with $\delta 4.8-5.2\left(\mathrm{CH}_{2} \mathrm{O}\right.$, 2). Dividing the value corresponding to $\delta 1.2$ $-1.4\left(\mathrm{COOCH}_{2} \mathrm{CH}_{3}, 3\right)$ by three gave the fraction of the peak intensity due to one proton. This number was then multiplied by two and subtracted from the integrated peak intensity of $\delta$ 3.7-4.0 $\left(\mathrm{CH}_{2} \mathrm{CH}_{2} \mathrm{O}, 4\right.$ and $\left.\mathrm{CH}_{2} \mathrm{CHO}, 2\right)$ to calculate the contribution by the $\beta$ protons in the 1-ethoxycarbonyloxyethylene units. The remainder was then used to determine the mol \% of oxyethylene units along the polymer chain.

The compositions of the polymeric esters, salts, and acids, calculated by this method (Table IX) agreed very well internally and also well with the compositions based on the results of sodium analy- 
Table IX. Composition of trioxane-ethyl glycidate-1, 3-dioxolane terpolymers ${ }^{\mathrm{a}}$

\begin{tabular}{|c|c|c|c|}
\hline Sample designation & TED-A & TED-B & TED-C \\
\hline $\begin{array}{l}\text { Mol \% of } 1 \text {-carboethoxy oxyethylene } \\
\text { units (based on PMR of the ester) }\end{array}$ & 1.0 & 1.8 & 2.0 \\
\hline $\begin{array}{l}\text { Mol \% of 1-carboethoxy oxyethylene } \\
\text { units (based on Na analysis of the salt) }\end{array}$ & 0.9 & 1.7 & 2.0 \\
\hline $\begin{array}{l}\text { Mol \% of oxyethylene units } \\
\text { (based on PMR of the ester) }\end{array}$ & 1.2 & 1.3 & 1.2 \\
\hline $\begin{array}{l}\text { Mol \% of oxyethylene units } \\
\text { (based on PMR of the salt) }\end{array}$ & 1.2 & 1.3 & 1.2 \\
\hline $\begin{array}{l}\text { Mol \% of oxyethylene units } \\
\text { (based on PMR of the acid) }\end{array}$ & 1.2 & 1.3 & 1.2 \\
\hline
\end{tabular}

sis of the polymeric salts.

An improved base-hydrolysis technique was utilized in this work to convert the crude polymeric ester terpolymer to the corresponding polymeric salt. The advantage of this "solution" technique (eq 5) over the slurry technique ${ }^{17}$ is ap-
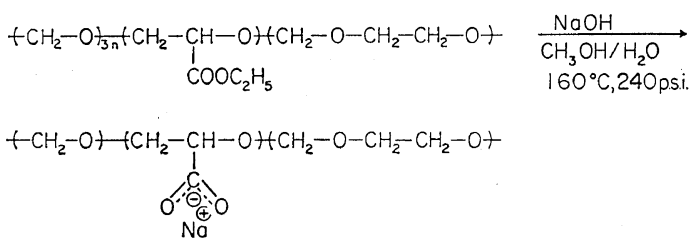

(5)

parent from infrared analysis of the product (Figure 4). Only $20 \%$ of the amount of sodium hydroxide, used in the slurry technique, was necessary to replace all of the ester carbonyl groups with the corresponding sodium carboxylate groups (in this case, the 5.8- $\mu$ absorption, due to the ester carbonyl, was almost completely absent).

The polymeric salt was converted to the free acid by treatment with $10-\% \mathrm{CH}_{3} \mathrm{COOH}$ in dioxane at room temperature for $3 \mathrm{~h}$ (eq 6).
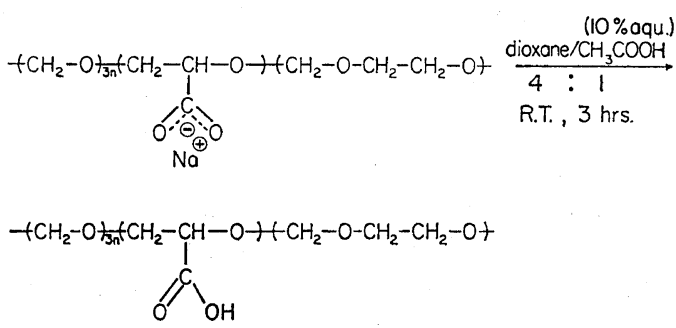

Infrared analysis were also carried out on thin films of the acid derivative of TED-A, prepared in a $\mathrm{KBr}$ pelletizer. After subjecting these films to a five-minute heat treatment at $160^{\circ} \mathrm{C}$ (in a Carver press) followed by fast cooling back to room temperature, a new peak at $5.6 \mu$ was observed to grow in the infrared spectrum of this "heattreated" acid (Figure 5). This peak is regarded

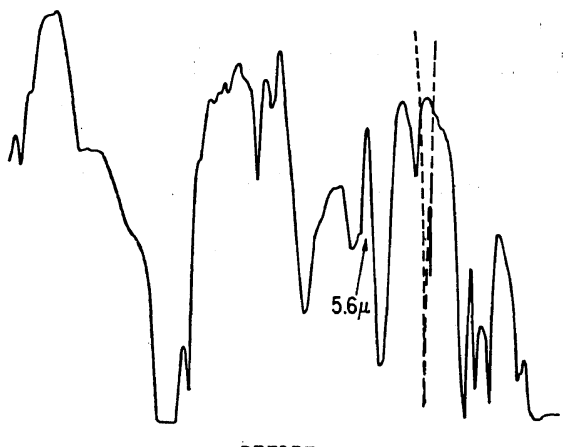

BEFORE

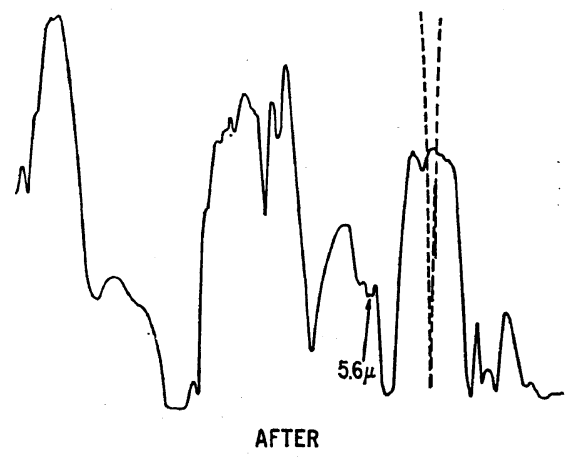

Figure 5. Infrared spectra of POM acids: A, before heat treatment; $\mathrm{B}$, after heat treatment. 
as evidence for the presence of anhydride in the sample. $0.02 \mathrm{~g}$ of the "heat-treated" acid were still soluble in $0.1 \mathrm{~m} l$ of hexafluoro-2-propanol, indicating that extensive crosslinking reactions had not occurred during the heat treatment. Similar results were also obtained for the acid derivatives of TED-B and TED-C terpolymers.

Various possible anhydride structures may be postulated for the polymeric anhydrides on the basis of these results. The formation of a sevenmembered cyclic anhydride would suggest the presence of short blocks of substituted oxyethylene units along the chain, whereas, a linear anhydride could only result from mild crosslinking reactions or from chain extension reactions between substituents near an endgroup. No distinction could be made on the basis of our IR analysis of the anhydride peaks.

Acknowledgements. This work was supported by a grant from the National Science Foundation. This paper was written when one of US (O.V.) was on sabbatical leave from the University of Massachusetts, a recipient of the Award of the Alexander von Humboldt Stiftung and a visiting professor at the Institute of Organic Chemistry, Free University of Berlin.

\section{REFERENCES}

1. R. W. Rees, British Patent 1,011,981 (1966).
2. P. J. Phillips, J. Polym. Sci., Part B, 10, 443 (1972).

3. C. P. O'Farrell and G. E. Serniuk, Ger. Offen. 2,211,901 (1972).

4. K. V. Martin and O. Vogl, U. S. Patent 3,284,411 (1966).

5. K. V. Martin, U. S. Patent 3,316,218 (1968).

6. L. P. DeMejo, W. J. MacKnight, and O. Vogl, Canadian High Polymer Forum, Abstr. of Papers, No. 17 (1975).

7. K. Weissermel, E. Fischer, K. H. Hafner, and H. Cherdron, Angew. Makromol. Chem., 415, 168 (1968).

8. K. F. Wissbrun, Makromol. Chem., 118, 211 (1968).

9. K. F. Wissbrun, F. M. Berardinelli, and M. B. Price, U. S. Patent 3,488,322 (1970).

10. A. B. Perstorp, French Patent 2,064,881 (1971).

11. O. Vogl, H. C. Miller, and W. H. Sharkey, Macromolecules, 5, 658 (1972).

12. H. Cherdron, J. Macromol. Sci., Chem., A6, 77 (1972).

13. W. H. Stockmayer and L. L. Chan, Polym. Prepr., Am. Chem. Soc., Div. Polym. Chem., 6, 333 (1965).

14. H. L. Wagner and K. F. Wissbrun, Makromol. Chem., 81, 14 (1965).

15. S. Penczek, J. Fejgin, P. Kubisa, K. Matyjaszewski, and M. Tomaszewicz, Makromol. Chem., 172, 243 (1973).

16. S. Slomkowski and S. Penczek, J. Chem. Soc., Sect. D 1347 (1970).

17. L. P. DeMejo, Ph. D. Thesis, University of Massachusetts, 1977. 